\title{
ORIGINAL ARTICLE International Spinal Cord Injury Pulmonary Function Basic Data Set
}

\author{
F Biering-Sørensen ${ }^{1}$, A Krassioukov ${ }^{2}$, MS Alexander ${ }^{3}$, W Donovan ${ }^{4}$, A-K Karlsson ${ }^{5}$, G Mueller ${ }^{6}$, I Perkash ${ }^{7}$, \\ A William Sheel ${ }^{2}$, J Wecht ${ }^{8,9}$ and GJ Schilero ${ }^{8,9}$
}

\begin{abstract}
Objectives: To develop the International Spinal Cord Injury (SCI) Pulmonary Function Basic Data Set within the framework of the International SCI Data Sets in order to facilitate consistent collection and reporting of basic bronchopulmonary findings in the SCI population.

Setting: International.

Methods: The SCI Pulmonary Function Data Set was developed by an international working group. The initial data set document was revised on the basis of suggestions from members of the Executive Committee of the International SCI Standards and Data Sets, the International Spinal Cord Society (ISCoS) Executive and Scientific Committees, American Spinal Injury Association (ASIA) Board, other interested organizations and societies and individual reviewers. In addition, the data set was posted for 2 months on ISCoS and ASIA websites for comments.

Results: The final International SCI Pulmonary Function Data Set contains questions on the pulmonary conditions diagnosed before spinal cord lesion, if available, to be obtained only once; smoking history; pulmonary complications and conditions after the spinal cord lesion, which may be collected at any time. These data include information on pneumonia, asthma, chronic obstructive pulmonary disease and sleep apnea. Current utilization of ventilator assistance including mechanical ventilation, diaphragmatic pacing, phrenic nerve stimulation and Bi-level positive airway pressure can be reported, as well as results from pulmonary function testing includes: forced vital capacity, forced expiratory volume in one second and peak expiratory flow. The complete instructions for data collection and the data sheet itself are freely available on the website of ISCoS (http://www.iscos.org.uk).
\end{abstract}

Spinal Cord (2012) 50, 418-421; doi:10.1038/sc.2011.183; published online 24 January 2012

Keywords: spinal cord injury; international data set; pulmonary function; pneumonia; sleep apnea; ventilator

\section{INTRODUCTION}

Pulmonary complications, in particular pneumonia, are a leading cause of death in individuals with spinal cord lesions the first year following injury, and along with cardiac disease the principal cause of death thereafter. ${ }^{1-3}$ Moreover, this is particularly the case in persons with complete spinal cord lesions and underscores the importance of recording basic information on bronchopulmonary function in daily practice when following individuals with spinal cord lesions. A spinal cord lesion may be traumatic or non-traumatic in etiology. All lesions to the spinal cord, conus medullaris and cauda equina are included in the present context.

The purpose of the International Spinal Cord Injury (SCI) Pulmonary Basic Data Set for individuals with spinal cord lesions is to standardize the collection and reporting of a minimal amount of information on bronchopulmonary function in daily practice in accordance with the purpose and vision of the International Spinal Cord Injury Data Sets. ${ }^{4}$ This will also make it possible to evaluate and compare results from various published studies and to guide future research.

The data in this International SCI Pulmonary Basic SCI Data Set generally will be used in connection with data in the International SCI
Core Data Set, ${ }^{5}$ which includes information on date of birth and injury, gender, the cause of spinal cord lesion and neurological status. In addition, the Core Data Set contains information on whether a vertebral injury was present, whether spinal surgery was performed, whether associated injuries were present, whether the patient with a spinal cord lesion was ventilator-dependent at the time of discharge from initial inpatient care, and the place of discharge from initial inpatient care.

It is extremely important that data be collected in a uniform manner from a scientific perspective as well as for improved patient care. For this reason, each variable and response category within each variable has specifically been defined in order to promote the collection and reporting of comparable minimal data.

Use of a standard format is essential for combining data from multiple investigators and locations. Various formats and coding schemes may be equally effective and could be used in individual studies or by agreement of the collaborating investigators. However, recommendations for variable names and database structure are available at the websites of the International Spinal Cord Society (ISCoS) (http://www.iscos.org.uk), and the National Institute of Neurological

${ }^{1}$ Clinic for Spinal Cord Injuries, NeuroScience Centre, Rigshospitalet, and University of Copenhagen, Copenhagen, Denmark; ${ }^{2}$ nternational Collaboration On Repair Discoveries (ICORD), University of British Columbia and Vancouver Coastal Health, Vancouver, British Columbia, Canada; ${ }^{3}$ Renown Rehabilitation Hospital, Reno, NV, USA; ${ }^{4}$ University of Texas Health Science Center, Baylor College of Medicine, Houston, TX, USA; ${ }^{5}$ Sahlgrenska University Hospital, Gothenburg, Sweden; ${ }^{5}$ Swiss Paraplegic Centre, Clinical Trial Unit, Nottwil, Switzerland; ${ }^{7}$ Stanford University and Veteran Administration Palo Alto, Palo Alto, CA, USA; ${ }^{8}$ The James J Peters Veterans Affairs Medical Center, Bronx, NY, USA and 9The Mount Sinai School of Medicine, New York, NY, USA

Correspondence: Professor F Biering-Sørensen, Clinic for Spinal Cord Injuries, NeuroScience Centre, RIGSHOSPITALET TH2091 and University of Copenhagen, 9 Blegdamsvej, DK-2100 Copenhagen $\varnothing$, Denmark.

E-mail: finbs@rh.dk

Received 26 September 2011; revised 8 December 2011; accepted 12 December 2011; published online 24 January 2012 
Disorders and Stroke (NINDS) the Common Data Elements Project website (http://www.CommonDataElements.ninds.nih.gov). ${ }^{6}$ This document was produced under the auspices of ISCoS and ASIA.

\section{METHODS}

An initial version of the International SCI Pulmonary Function Basic Data Set was prepared by a working group consisting of the authors. All members in this group have clinical and research experience with the topic of the data set. These efforts were guided by the need to prepare a basic data set that could be used by clinicians in various settings and countries without cost or the need of advanced technical equipment. The data collected would provide the minimal amount of standardized information necessary for a basic pulmonary evaluation of the SCI patient. In order to ensure consistency in the data collection and to facilitate interpretation, detailed information is provided in a syllabus for each specific variable and each response category.

The process for developing this version of the International SCI Pulmonary Function Basic Data Set followed the steps given below:

1. The working group of the International SCI Pulmonary Function Basic Data Set finalized the first draft during extensive e-mail contact among the group members.

2. The data set was reviewed by members of the Executive Committee of the International SCI Standards and Data Sets.

3. Comments from the Committee members were discussed in the working group and appropriate adjustments were made to the data set.

4. Members of the ISCoS Executive and Scientific Committees and ASIA Board were also asked to review the data set.

5. Comments from the Committee/Board members were discussed in the working group and a response was made and further adjustments of the Data Set were performed.

6. Relevant and interested scientific and professional (International) organizations and societies (around 40) and individuals were also invited to review the data set. In addition, the data set was posted on the ISCoS and ASIA websites for over 2 months to allow comments and suggestions.

7. Comments were discussed and responded to by the working group. Where appropriate, adjustments to the data set were made.

8. To conclude this part of the consultation, members of the ISCoS Executive and Scientific Committees and ASIA Board members received the data set for final review and approval.

9. The International SCI Pulmonary Function Basic Data Set was then further scrutinized by the team working on the NINDS, Common Data Elements Project, in cooperation with the Executive Committee of the International SCI Standards and Data Sets Committees. ${ }^{6}$

10. Finally, the data set was used to collect information on several cases to confirm its function in actual practice.

\section{RESULTS}

The data sheet is included in the Appendix and the data sheet and syllabus are available on the ISCoS website (http://www.iscos.org.uk).

Listed below are the variables included in the International SCI Pulmonary Function Basic Data Set:

\section{Date of data collection}

Because the collection of data on bronchopulmonary conditions may be performed at any time following the spinal cord lesion, the date of data collection is imperative for computing the time that has lapsed after the initial spinal cord lesion. This will permit the information obtained to be related to other data collected on the same individual at various time points.

Pulmonary conditions present before spinal cord lesion (collected once)

This variable documents the history of pulmonary diseases such as asthma, chronic obstructive pulmonary disease (COPD), including chronic bronchitis, and emphysema, sleep apnea and other specified conditions that pre-date the spinal cord lesion. We recognize that these pulmonary conditions are highly complex and have degrees of severity. For example, COPD can be classified as at risk, mild, moderate, severe or very severe based on post-bronchodilator forced expiratory volume in one second (FEV1) values. However, because of the necessity for simplicity, these types of additional evaluative procedures have not been incorporated into the data collection procedures.

These conditions include pulmonary conditions diagnosed before the spinal cord lesion that may negatively impact pulmonary function. Asthma and COPD are relatively common conditions associated with airflow obstruction. If the information has been documented once, it is not necessary to fill in this variable again to avoid redundant data.

\section{Smoking history}

This variable documents the smoking history, and quantifies smoking by average daily use and by the number of pack-years smoked.

The SCI individual is categorized as: never smoked, former smoker or current smoker. If a former smoker, the year he/she quit smoking is reported, if a former or current smoker, the number of years he/she smoked is recorded, as well the average number of cigarettes/cigars/ pipes smoked on a daily basis. On the basis of this information it is possible for former or current smokers to calculate the number of pack-years of smoking:

$$
\begin{aligned}
& {[(\text { average number smoked daily }) / 20] \times(\text { number of years smoked })} \\
& \quad=\text { pack }- \text { years. }
\end{aligned}
$$

When judging bronchopulmonary issues in individuals with spinal cord lesions, the influence of smoking is an important factor. ${ }^{7-9}$

\section{Pulmonary complications and conditions after the spinal cord lesion within the last year}

This variable documents pulmonary complications or conditions occurring after the spinal cord lesion and within the last year. These are pneumonia, including number of episodes of pneumonia treated with antibiotics, and number of episodes of pneumonia requiring hospitalization; asthma; COPD, chronic bronchitis and emphysema; Sleep apnea; and other respiratory conditions, which are specified.

Pneumonia is one of the leading causes of mortality in individuals with spinal cord lesions, ${ }^{1-3}$ therefore it is important to record this information in detail whenever possible. Other respiratory complications and conditions may develop after sustaining a spinal cord lesion, including atelectasis (lung collapse), and other disorders with high disease prevalence in the general population (that is, asthma, COPD).

Sleep apnea, either obstructive or central in etiology, is a common yet frequently unrecognized condition among individuals with spinal cord lesions. ${ }^{10,11}$ Sleep apnea may adversely affect sleep quality and daytime functioning, and studies in the general population suggest that obstructive sleep apnea is an independent risk factor for hypertension, stroke and myocardial infarction. ${ }^{12}$

\section{Current utilization of ventilatory assistance}

This variable documents any assistance device utilized at the time of evaluation to augment ventilation, that is, None; Mechanical ventilation for $<24 \mathrm{~h}$ per day, for $24 \mathrm{~h}$ per day; or for an unknown number of hours per day; Diaphragmatic pacing device, and date it was inserted; Phrenic nerve stimulation, and date it was inserted; Bi-level positive airway pressure, and date started use; and Other, as specified.

Respiratory insufficiency is common following spinal cord lesions. Ventilatory assistance devices include, but are not limited to mechan- 
ical ventilators, diaphragmatic pacers, phrenic nerve stimulators, and Bi-level positive airway pressure. These devices do not include routine administration of oxygen, intermittent positive pressure breathing, continuous positive airway pressure, or external negative pressure devices. Wording of this variable reflects the International Spinal Cord Injury Core Data Set for the type of ventilatory assistance used to sustain respiration at discharge after the initial rehabilitation period following the spinal cord lesion. ${ }^{5}$ This variable takes into account that the type of ventilatory assistance may have changed since discharge from the initial inpatient period.

\section{Pulmonary function tests performed}

Forced vital capacity (FVC-in Litres) and forced expiratory volume in one second (FEV1-in Litres) are measured by spirometry. The FVC is defined as the total volume of air that a person can forcibly exhale during a maximal expiratory effort, and FEV1 is the volume of air expired in the first second of the FVC maneuver. Peak expiratory flow (in Liters/minute) is the maximal expiratory flow rate achieved during the FVC maneuver.

The FVC, FEV1 and peak expiratory flow are important global measures of pulmonary function that are variably influenced by a variety of factors including level of spinal cord lesion, time since the lesion, age, respiratory muscle strength, environmental factors (that is, cigarette smoking), and concomitant respiratory conditions. ${ }^{7-9,13,14}$

\section{DISCUSSION}

The data collected in the International SCI Pulmonary Function Basic Data Set will be available in conjunction with the data in the International SCI Core Data Set, which among other items, includes information on date of birth and injury, gender, the cause of SCI, and neurological status. ${ }^{5}$ To make this basic data set as useful as possible in a clinical setting, we have kept the number of items as small as possible. However, the working group finds that the items included cover the most clinically relevant information regarding possible bronchopulmonary dysfunction in individuals with a spinal cord lesion. The working group recognizes that information in the International SCI Pulmonary Function Basic Data Set could be extended by other clinically important information, whenever appropriate.

To facilitate the use of the International SCI Data Sets, this International SCI Pulmonary Function Basic Data Set and its data collection (the form is included in the Appendix) have been developed similar to that of previous International SCI Basic Data Sets. To validate and translate this data set into use, additional effort and study will be needed. In this respect, it is additionally advised to adhere to the recommendations given by the Executive Committee for the International SCI Standards and Data Sets. ${ }^{15}$ The authors invite all those who are interested to participate in this open and ongoing process.

\section{DATA ARCHIVING}

There was no data to deposit.

\section{CONFLICT OF INTEREST}

The authors declare no conflict of interest.

\section{ACKNOWLEDGEMENTS}

Coloplast A/S, Denmark has supported the work with this Data Set with an unconditional grant. We are thankful for comments and suggestions received from Lawrence Vogel, Susan Charlifue, Gordana Savic and Michael DeVivo.

1 Hartkopp A, Brønnum-Hansen H, Seidenschnur AM, Biering-Sørensen F. Survival and cause of death after traumatic spinal cord injury. A long-term epidemiological survey from Denmark. [published erratum in: Spinal Cord 1997;35(12):862-4]. Spinal Cord 1997; 35: 76-85.

2 DeVivo MJ, Krause JS, Lammertse DP. Recent trends in mortality and causes of death among persons with spinal cord injury. Arch Phys Med Rehabil 1999; 80: 1411-1419.

3 Lidal IB, Snekkevik H, Aamodt G, Hjeltnes N, Biering-Sørensen F, Stanghelle JK. Mortality after spinal cord injury in Norway. J Rehabil Med 2007; 39: 145-151.

4 Biering-Sorensen F, Charlifue S, DeVivo M, Noonan V, Post M, Stripling T et al. International spinal cord injury data sets. Spinal Cord 2006; 44: 530-534.

5 DeVivo M, Biering-Sørensen F, Charlifue S, Noonan V, Post M, Stripling T et al. International spinal cord injury core data set. Spinal Cord 2006; 44: 535-540.

6 Biering-Sørensen F, Charlifue S, Devivo MJ, Grinnon ST, Kleitman N, Lu Y et al. Incorporation of the international spinal cord injury data set elements into the national institute of neurological disorders and stroke common data elements. Spinal Cord 2010; 49: 60-64.

7 Linn WS, Spungen AM, Gong Jr H, Bauman WA, Adkins RH, Waters RL. Smoking and obstructive lung dysfunction in persons with chronic spinal cord injury. J Spinal Cord Med 2003; 26: 28-35.

8 Jain NB, Brown R, Tun CG, Gagnon D, Garshick E. Determinants of forced expiratory volume in 1 second (FEV1), forced vital capacity (FVC), and FEV1/FVC in chronic spinal cord injury. Arch Phys Med Rehabil 2006; 87: 1327-1333.

9 Stolzmann KL, Gagnon DR, Brown R, Tun CG, Garshick E. Longitudinal change in FEV1 and FVC in chronic spinal cord injury. Am J Respir Crit Care Med 2008; 177: 781-786.

10 Leduc BE, Dagher JH, Mayer P, Bellemare F, Lepage Y. Estimated prevalence of obstructive sleep apnea-hypopnea syndrome after cervical cord injury. Arch Phys Med Rehabil 2007; 88: 333-337.

11 Berlowitz DJ, Brown DJ, Campbell DA, Pierce RJ. A longitudinal evaluation of sleep and breathing in the first year after cervical spinal cord injury. Arch Phys Med Rehabil 2005; 86: 1193-1199.

12 Biering-Sørensen $F$, Jennum P, Laub M. Sleep disordered breathing following spinal cord injury. Respir Physiol Neurobiol 2009; 169: 165-170.

13 Spungen AM, Dicpinigaitis PV, Almenoff PL, Bauman WA. Pulmonary obstruction in individuals with cervical spinal cord lesions unmasked by bronchodilator administration. Paraplegia 1993; 31: 404-407.

14 Linn WS, Spungen AM, Gong Jr H, Adkins RH, Bauman WA, Waters RL. Forced vital capacity in two large outpatient populations with chronic spinal cord injury. Spinal Cord 2001; 39: 263-268.

15 Biering-Sørensen F, Alexander MS, Burns S, Charlifue S, Devivo M, Dietz V et al. Recommendations for translation and reliability testing of international spinal cord injury data sets. Spinal Cord 2011; 49: 357-360.

\title{
APPENDIX
}

\section{INTERNATIONAL SPINAL CORD INJURY PULMONARY BASIC DATA SET FORM (Version 1.0)}

\author{
Date performed: YYYY/MM/DD
}

Pulmonary conditions present before spinal cord lesion (collected once):

$\square$ None

$\square$ Asthma

$\square$ Chronic obstructive pulmonary disease (includes emphysema and chronic bronchitis)

$\square$ Sleep apnea

$\square$ Other, specify

$\square$ Unknown 
Smoking history:

$\square$ Never smoked $\quad \square$ Former smoker $\quad \square$ Current smoker $\quad \square$ Unknown

If a former smoker, which year did you quit smoking?

If a former or current smoker, for how many years did (have) you smoked? years

If a former or current smoker, on average how many (cigarettes/cigars/pipes) do (did) you smoke on a daily basis (answer all that apply): cigarettes cigars pipe bowls

$\square$ unknown

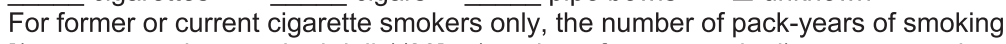

[(average number smoked daily)/20] x (number of years smoked):

pack-years

Pulmonary complications and conditions after the spinal cord lesion within the last

year:

$\square$ None

$\square$ Pneumonia: Number of episodes of pneumonia treated with antibiotics: Number of episodes of pneumonia requiring hospitalization:

$\square$ Asthma

$\square$ Chronic obstructive pulmonary disease (includes emphysema and chronic bronchitis)

$\square$ Sleep apnea

$\square$ Other respiratory conditions, specify

$\square$ Unknown

\section{Current Utilization of Ventilatory Assistance:}

$\square$ None

$\square$ Mechanical Ventilation: $\square$ Yes, less than 24 hours per day

$\square$ Yes, 24 hours per day

$\square$ Yes, unknown number of hours per day

$\square$ Diaphragmatic pacing: Date inserted: YYYY/MM/DD

$\square$ Phrenic nerve stimulation:Date inserted: YYYY/MM/DD

$\square$ Bi-level Positive Airway Pressure (BiPAP)Date started use: YYYY/MM/DD

$\square$ Other, specify

$\square$ Unknown

Pulmonary function tests:

Date performed: YYYY/MM/DD

Forced vital capacity (FVC):

Forced expiratory volume in one second (FEV1):

Peak expiratory flow (PEF): Liters/minute Liters 